Original Research Paper

\title{
Towards Low Emission Development: Prospects of Applying MBIs in the Industrial Sector of Central Java, Indonesia
}

\author{
Agung Sugiri and Imam Buchori \\ Department of Urban and Regional Planning, Diponegoro University, Semarang, Indonesia
}

\section{Article history}

Received: 10-02-2016

Revised: 27-05-2016

Accepted: 04-06-2016

Corresponding Author:

Agung Sugiri

Department of Urban and

Regional Planning, Diponegoro

University, Semarang,

Indonesia

Email: agung.sugiri@uqconnect.edu.au

\begin{abstract}
In dealing with pollution or emission, including in encouraging Low Emission Development (LED) as an acceptable strategy for climate change mitigation, Indonesia applies Command and Control (CAC) approach through regulations on environmental and pollution standards. However, the enforcement is characterized by weak monitoring and controlling due to aspects like non-compliant industries and lack of personnel and equipment of the corresponding agencies. Introducing Market Based Instruments (MBIs) can help better achievement in LED as evidenced in the USA, Australia, Taiwan, South Korea and Thailand. This study aims to answer the question "how can the Central Java Provincial Government (CJPG) facilitate better LED through the application of MBIs in the industrial sector?" The approach is qualitative through in-depth interviews with key persons from the CJPG and manufacturing industries with high rate of greenhouse gas emissions in Semarang and Surakarta metropolitans as the two largest industrial centers in Central Java. The results show that the CJPG cannot apply MBI approach in its purely theoretically forms. Instead, it is the principle, which is in accordance with the Equity-Based Development model that should be integrated into the CAC application, i.e., the polluters pay principle. The existing programs, like PROPER, should be refined conceptually and enforced more widely to accommodate 'internalizing the externality' principle better. More industries should be encouraged to participate in such programs.
\end{abstract}

Keywords: Climate Change Mitigation, Command and Control, EquityBased Development, Low Emission Development, Market-Based Instruments

\section{Introduction}

Indonesia is one of the countries committed to addressing the problem of climate change. The National Action Plan to reduce Greenhouse Gas (GHG) emissions (RAN-GRK) has been legalized as the Presidential Decree No. $61 / 2011$. Emission reduction target is $26 \%$ if business as usual, which means no international help available and a maximum of $41 \%$ if the carbon market mechanism works well (Jupesta, 2010). Soon after, the Local Action Plan to reduce emissions of greenhouse gases, RAD-GRK 2010-2020, of Central Java province has also been completed and has been legalized as the Governor Regulation No. 43/2012. This plan focuses on mitigation of climate change, with the goal of reducing greenhouse gas emissions so that the environmental damage caused by climate change can be reversed in the long term.
Unfortunately, a study initiated by GIZ concluded that the Central Java Provincial Government is not yet ready to implement RAD-GRK (Sugiri, 2015). The level of preparedness of Central Java Provincial Government in general is 3.47 (out of 5), which means a little more than half prepared and will require much assistance. Moreover, among the six main sectors (industry sector, the forestry sector, transport sector, energy sector, the waste sector and the agricultural sector), the industrial sector is the least prepared with a score of 1.75 .

The main strategy of mitigating climate change is generally Low Emission Development (LED). This approach seeks to keep economic growth high while reducing the GHG emissions. Thus, the industrial sector becomes a vital priority. Significant emissions, mainly from large- and medium-scale manufacturing industries 
in Central Java, coupled with poor readiness management would be sufficient to raise doubts that the emission reduction targets can be achieved.

The manufacturing sector is paramount in the development of Central Java. Growth in this sector is always above $6 \%$ per year since Indonesia managed to escape from the crisis of 1998-99, always exceeding the annual economic growth of Central Java and Indonesia. Meanwhile, the contribution of all activities of the secondary sector in the economy of Central Java is about $40 \%$, which is well above the share of primary sectors, which means that the economy has been based on manufacturing industries. It is natural for this sector that a significant role in reducing $\mathrm{GHG}$ emissions is expected. Therefore, as concluded by an earlier study (Sugiri, 2015), there is a need for an innovative effort in the industrial sector in Central Java.

While the previous study (Sugiri, 2015) has produced valuable recommendations for the industrial sector's stakeholders (particularly the Trade and Industrial Agency/Disperindag) to be more prepared, this study will highlight the innovative approach that can encourage better LED. Commonly known are two approaches, namely Command and Control (CAC) and Market-Based Instruments (MBIs). Indonesia, including Central Java, applies CAC approach in full.

The main characteristic is the presence of regulations of environmental quality and effluent standards and specific sanctions for those who violate the rules. Meanwhile, MBIs use market mechanisms with instruments such as a tax or a compensation fund and the price system. Both are based on the same principle, namely those who pollute are responsible for the cost of the environmental damage (polluters pay principle). This principle is apparently a sense of justice and therefore consistent with the Equity-Based (Regional) Development (EBRD) proposed by Sugiri (2009), especially in the production function.

However, when the CAC is compared with MBIs, MBIs provide opportunities for higher economic activity with the same level of environmental damage. Also, the cost of environmental improvements can be made available earlier on MBIs. Besides, related to the implementation, $\mathrm{CAC}$ is more prone to corruption, especially in countries with a long history of corruption such as Indonesia.

Thus, it would be good if the industrial sector in Central Java can couple the CAC with MBI approach so that successful mitigation of climate change can be more assured. Therefore, this study aims to answer the question: "How can the Central Java Provincial Government (CJPG) facilitate better LED through the application of MBIs in the industrial sector?" Figure 1 shows a map of the study area, Central Java Province, with major roads and boundaries of administrative districts and towns.

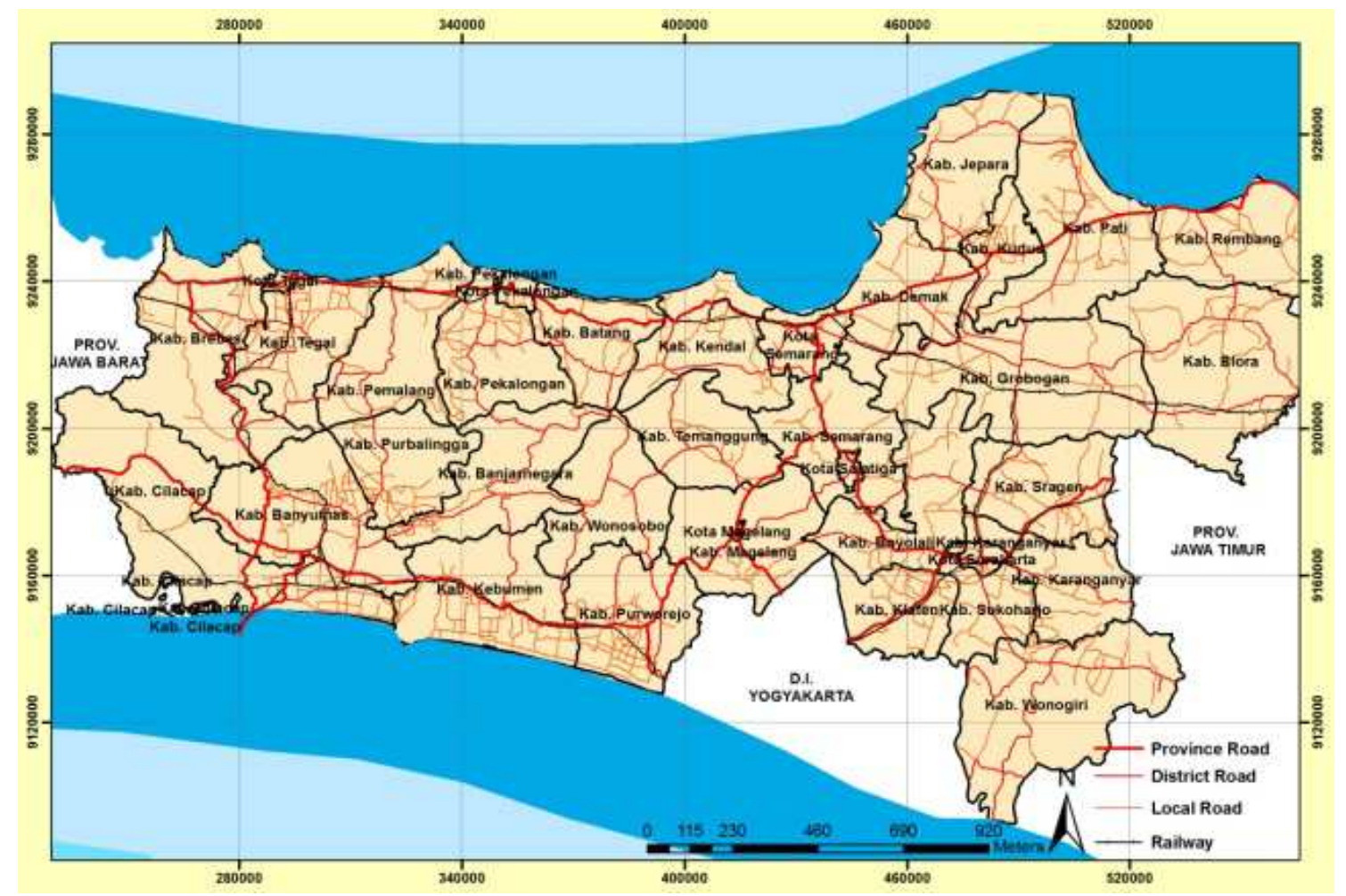

Fig. 1. Map of central Java Province, Indonesia 


\section{Literature Review}

Literature review begins with discussing the importance of low emission development in ensuring sustainable development. It will be shown that high GHG emissions tend to be inequity and hence the equity-based development model is a valid framework to support the development with low emissions. The discussion will continue with a comparison of approaches in dealing with emissions/pollution, i.e., between CAC and MBIs. Lastly, the review will construct research propositions to be confirmed in the case of the industrial sector in Central Java.

\section{Low Emission Development in Sustainable Development}

In climate change mitigation, low-emission development strategy is deemed appropriate. It is reasonable because, with the same level of production, lower GHG emissions will certainly be better able to ensure sustainable development.

\section{Ensuring Sustainability through Equity-Based Development}

In line with the definition of sustainable development by the WCED (1987), sustainable regional development is development at the region or city level that can ensure equity within and between generations without reducing the ability of other related regions to do the same thing (Sugiri, 2009; Sugiri et al., 2011). The concept of Equity-Based (Regional) Development (EBRD) by Sugiri (2009) can address the challenges of sustainability, particularly for resource-rich economies like Indonesia. Studies applying the concept have been on various issues, from spatial inequality (Sugiri and Nuraini, 2013), in which the researchers have found that it is inequity that should be addressed first to resolve the spatial inequality problem, to sustainability assessment of the Semarang metropolitan development (Buchori et al., 2015).

This model confirms the four functions to be assured with the application of equity, namely the distribution of benefits (I), the production function (II), non-production functions (III) such as ecological, conservation and buffer functions and reinvestment for sustainability (IV). The concept corresponds to the relevant current literature (Ituarte-Lima et al., 2014; McDermott et al., 2013). McDermott et al. (2013), for example, classifying justice into distributive justice, procedural justice and contextual fairness, which all three types are included in the EBRD. Figure 2 shows the model of EBRD.

Results of the development process, of course, is the welfare of the population, while the input is of three types of capital, namely natural resources $(\mathrm{Kn})$, physical or human-made $(\mathrm{Kp})$ and human capital (Kh). The development process itself includes the four functions mentioned above.

The role of natural resources is critical, especially given the need to preserve the environment and sustainable development. Some aspects of the role of natural resources can be replaced by human-made capital, but this only concerns the production function alone.

Natural resources are used in the production function as an input of material and energy. The results are benefits recorded as, for example, the Gross Domestic Product (GDP). Also, natural resources are needed for the non-production function or environmental sustainability. These benefits, such as keeping the assimilative capacity, biodiversity, comfortable microclimate and prevent global warming, are vital though not recorded in the data or economic statistics.

However, keep in mind, the non-production functions must be supported by the fourth function, namely reinvestment for sustainability. If it goes well, the authority of the city, region or country will have enough funds to repair damage to the environment and restore the carrying capacity, because an appropriate portion of benefits, especially from the production function, will be invested for sustainability purposes. The idea of the carbon market, for example, is consistent and can be done in the framework of this fourth function. Only with a mechanism like this (Fig. 2) sustainable development can be ensured.

In mitigating climate change, the production function is crucial because GHG emissions come from this feature. However, the value of the function is often regarded as too small compared to the actual value, especially in the previous era when there was only a little awareness of sustainable development. It is because many of the cost items are not included in the existing market mechanism (market failure). An industry that produces pollutants that harm the environment and surrounding community is an example. Of course, it takes money to repair the environmental damage and compensate the community, but all these are not included in the production cost structure of the industry. So, it is a negative externality.

\section{High Level of GHG Emissions is an Equity Failure}

Development benefits resulting from the production and non-production functions are distributed to residents through socio-economic mechanism. Thus, according to the concept of equitybased development, equity should be applied to all the mechanisms of the four functions (Sugiri, 2009). 


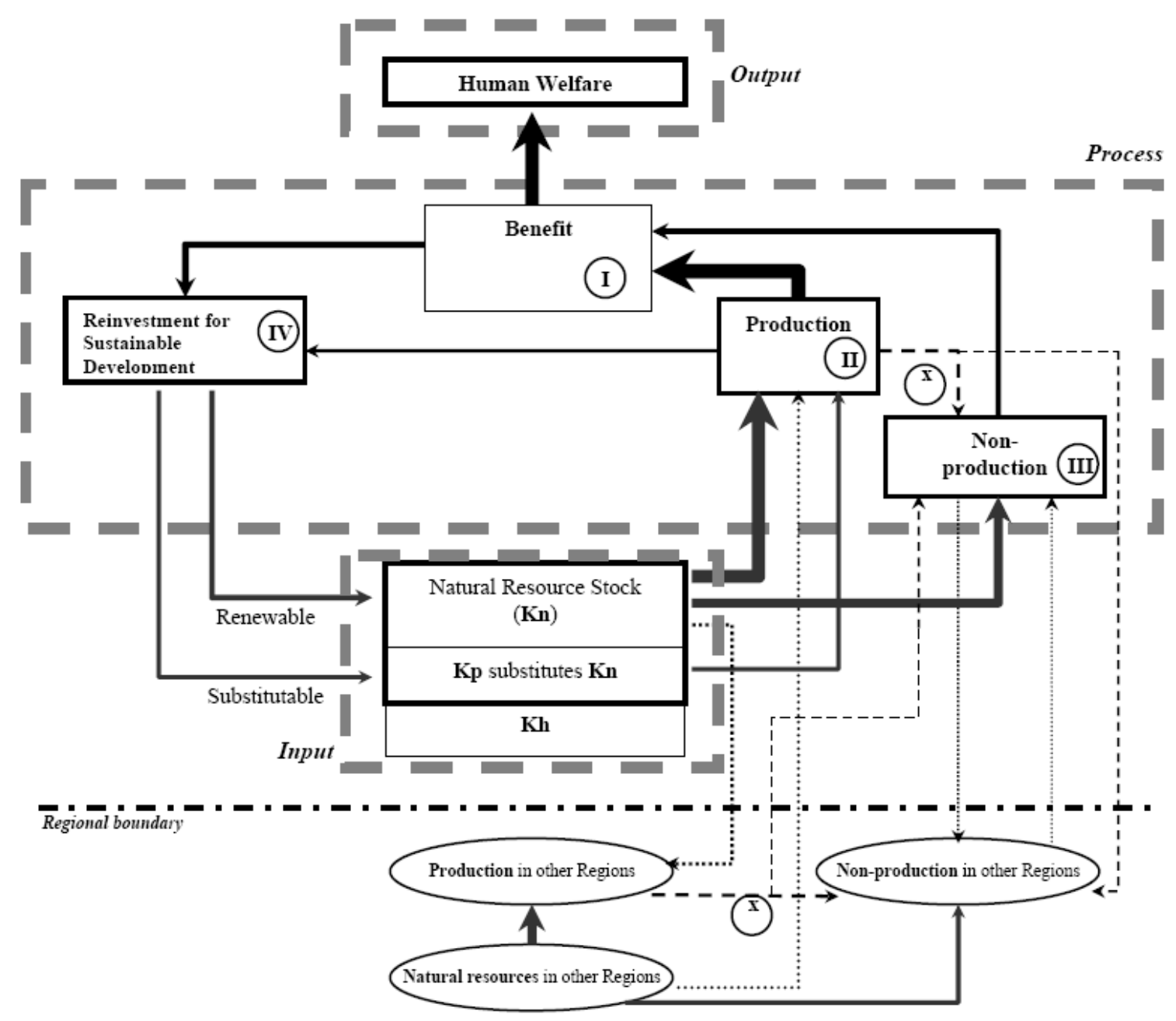

Fig. 2.Inter-regional model of equity-based development (Sugiri, 2009: 117); Notes: I: Equity I; II: Equity II; III: Equity III; IV: Equity IV; All arrows represent positive flows, except the ' $x$ ' arrow which is negative externality, i.e., the negative impact of the production function to the non-production function; however, it is hardly captured by the market mechanism (the market failure)

Equity on the production function will then be referred to as equity II. In the classification of McDermott et al. (2013), this includes the type of procedural and distributive justice. The production process involves the large and small economic stakeholders in the upstream in the form of natural resource extraction while in the downstream there is a variety of industries and associated services. Public policy should be able to ensure fairness in managing this function because if not, there will be equity failures in terms of high economic inequality and the threat of unsustainability (Sugiri, 2009).

The unsustainability indications, including the impacts of climate change, are already evident lately. First, the exploitation of natural resources takes place at a very high level. In the EBRD, this is called equity failure IIc. The production process pursuing high economic growth without appropriate reinvestment for sustainability (function IV) is an equity failure that may result in unsustainability. Secondly, severe negative externalities of economic activity are there, in the form of air, water and soil pollutions that damage the environment, as well as high GHG emissions (equity failure IId). Thus, the high level of GHG emissions from economic activities can be considered a negative externality and inequity.

The phenomena of excessive GHG emissions and this kind of equity failure can be explained through a graphical analysis in Fig. 3. Buchori and Sugiri (2016) have done a theoretical analysis of sustainable and unsustainable situation by combining environmental economic analysis (Pearce and Turner, 1990) and threshold and environmental limits (Munro 1995; Kozlowski, 1993; Daly, 1991). 


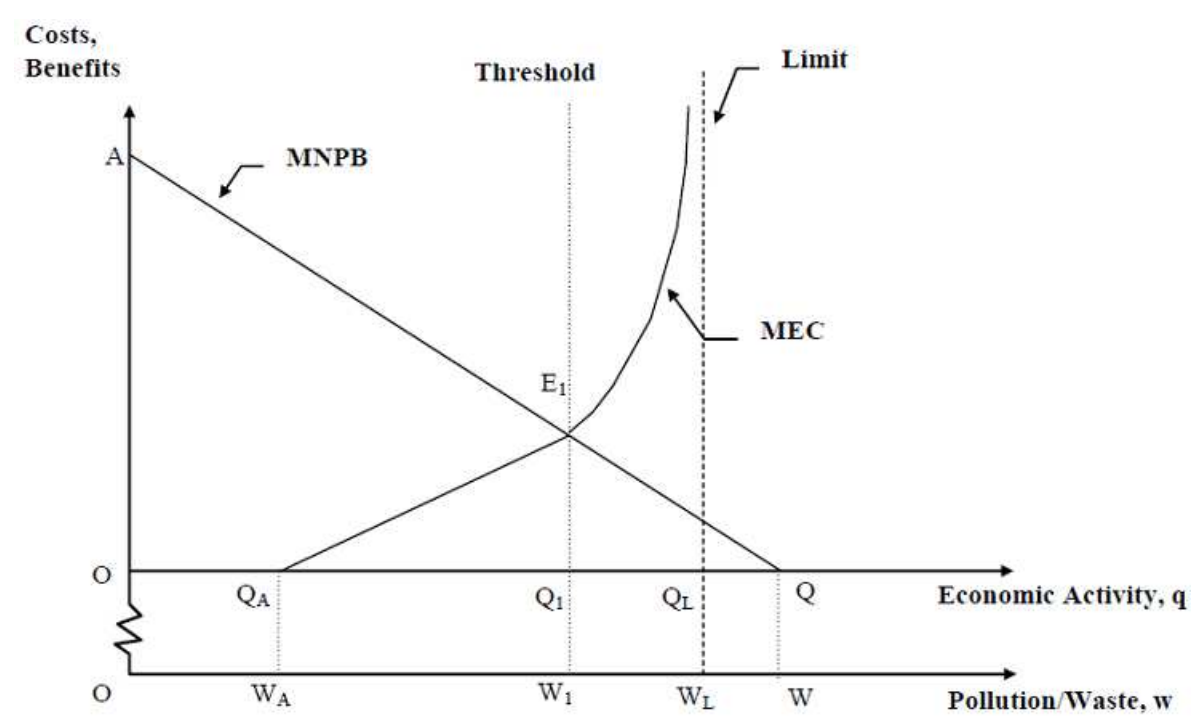

Fig. 3. Hypothetical Analysis of Sustainable and Unsustainable Situation (Buchori and Sugiri, 2016)

In Fig. 3, environmental damage is simplified by the level of pollution or waste, or GHG emissions if it relates to climate change. The assumption is that the greater the degree of economic activity the greater the level of pollution. There are two elements in the picture, namely pollution and externalities. The side of the polluter (i.e., actors of the economic activity) is shown by the MNPB curve (Marginal Net Private Benefit), i.e., the revenue minus the cost for an additional unit of output. On the other hand, the externalities borne by the public is indicated by the MEC curve (Marginal Externality Cost). The assumption is that the increase in economic activity will be followed by the rise in externalities.

Meanwhile, the assimilative capacity of the environment is able to absorb the maximum amount of $\mathrm{OW}_{\mathrm{A}}$ units of pollution/waste without causing any external cost. Thus, the MEC curve begins after the economic activity exceeds $\mathrm{OQ}_{\mathrm{A}}$ units. Without consideration of externalities, the economy will grow to OQ level to obtain the maximum benefits (the area of OAQ). This situation is a market failure. It may also not be sustainable because economic activities may exceed the environmental limit to support them. The environmental limit is indicated by the $\mathrm{OQ}_{\mathrm{L}}$ level of economic activity. It means that the environment cannot receive more than $\mathrm{OW}_{\mathrm{L}}$ units of pollution because the damage cannot be repaired.

To be sustainable, economic activity should not exceed the carrying capacity of the environment (Mitchell, 1979). Meanwhile, the "threshold to further development is encountered if cannot extend to a new area, produce additional output, achieve higher quality, or accelerate production, without involving an increase of investment, social or ecological cost" (Kozlowski,
1993: 19). So, if it passes the environmental threshold, the marginal external cost will be much more expensive as shown by the MEC steeper curve in Fig. 3. So, sustainable economic activities, will achieve the maximum benefits (the area of $\mathrm{OAE}_{1} \mathrm{Q}_{\mathrm{A}}$ ) at $\mathrm{OQ}_{1}$ level with a pollution level of $\mathrm{OW}_{1}$.

Economic activity that is at the levels between the threshold and the limit is not an efficient for the society. This situation will be an equity failure because the external cost incurred by the public will be much higher. On the other hand, the environmental damage caused by the activities is most probably difficult to cure. Thus, this situation is not sustainable because it does not encourage intra- and intergenerational equity. If the polluters pay principle applies, the $E_{1}$ balance will be achieved. The level of economic activity will be at a sustainable level, $\mathrm{OQ}_{1}$.

It is apparent that low-emission development strategy, or first known as the Clean Development Mechanism (CDM) of the Kyoto Protocol (Erickson et al., 2014; Buchner et al., 2007), is appropriate. Thus, the approach taken to ensure the low GHG emissions must be able to fully support the implementation of the strategy.

\section{Best Approach for Low Emission Development: CAC or MBI?}

MBI approach is an attempt to correct the market failures that harm the environment. The USA, which widely applies MBI, is among the pioneers of environmental improvement since 1970 (Halter, 1991; O'Connor, 1994; Tietenberg, 1994). The principle is simple, i.e., the polluter must pay for reversing the environmental damaged caused (polluters pay principle). The technique is to use market instruments especially the 
tax system (environmental taxes and pollution/emission taxes) and tradeable emission licenses/permits (Liu et al., 2014; Doran and Ginnochio, 2008).

The equity failures IIc and IId cause environmental injustice. However, due to the market failure that is generally more severe in developing countries like Indonesia, with the growing impacts of climate change, regions with low economic level have suffered more than those with high economic one (Grineski et al., 2012; Patil and Deepa, 2007). It is a form of spatial inequality in the environmental aspects. Even more alarming is the loss due to environmental degradation that must be borne by the community in various ways, such as health cost rise due to more frequent illness, or reduced income for farmers and peasants due to the arable land is becoming less fertile. Meanwhile, the environmental repair cost must be borne by the government.

This is due to the approach in handling the environmental degradation and the increasing GHGs chosen by the Indonesian government, which is Command and Control (CAC) through a set of regulations, pollution/emission quality standards and sanctions. As a result, the government and the community often still have to bear the costs of the environmental improvement, although there is no violation of any regulation by the polluters. It has become something that people are aware of and local governments often complain. Something that is not fair is happening here and it has emphasized the need to study innovative approaches for the low-emission development.

\section{The Propositions}

Propositions of this study, based on the literature review above, are:

- $\quad$ MBI approach is more beneficial than the CAC for the economy of Central Java. As discussed above, some of the advantages of the MBI will lead to better prospects for the low-emission, sustainable, development, which also means the successful mitigation of climate change

- The existing CAC approach should be equipped with MBI. The type of MBIs that is appropriate for the initial stage of the application in the industrial sector of Central Java is the tradeable emission permits

- To apply MBI approach, the taxation system should be reformulated to accommodate it related to lowemission development in the industrial sector. Reformulation of the tax regime should be carried out within the existing framework of taxation, so that implementation can be easier.

This proposition set has been confirmed in the field, namely the industrial sector in Central Java.

\section{Methodology}

\section{Approach and Stages of the Research}

As can be seen from its inquiry, this study is based on a philosophy of social constructivism, which sees the stakeholders involved in the industrial development of Central Java, as far as their interests are concerned, are more aware. So, proposing any measure to encourage the growth of industrial sector while reducing GHG emissions should be based on their constructs, or otherwise it would be difficult to implement. Therefore, the research approach and methods are qualitative (Yin, 2009; Creswell, 2009).

Four stages have been completed in the research. First, preparation was made, comprising literature review and research design. Having the research design in hand, confirmation of the propositions began with an observation and collecting data from the field. In-depth interviews were done with the key persons from the CJPG (two persons), the industry (two persons) and an Australian environmental expert whose origin is Indonesia. The CJPG institutions are the BLH (Environmental Management Board) and the Disperindag (Trade and Industrial Agency).

The sampling method was purposive, which is nonrandom and quite commonly used in qualitative research. The first and foremost key informant was Mrs. Evi Darmiyanti, an official from BLH whose authority is to manage and control pollution/emission from economic activities in Central Java. She then advised us about whom we should interview from other governmental agencies as well as industrial companies. She suggested us the institutions and the contact persons, who were the authorized managers. It is unfortunate that not all key informants suggested were able to be interviewed. It was due to various reasons discussed in the limitations section. For example, no official from the Taxation Office agreed to be interviewed. The third stage has also been done by compiling, systematizing and analysing the data and information. Finally, the fourth phase has been to conclude and to give relevant recommendations based on the findings.

\section{Confirmation of the Propositions}

There are four possible outcomes of this confirmation. First, the findings confirm the proposition exactly. In this regard, this study will be sort of 'theory testing' so that lessons learned are practical. The second alternative is that the findings only confirm some parts of the proposition set. If this is the case, in addition to contributing practically, this research would provide meaningful learning for the development of the EBRD model. Certain characteristics of the Central Java region may make the model cannot be applied completely and such kind 
of findings is certainly important for the improvement of the model.

Third, the study findings confirm not only all the propositions but also additional aspects. It will also refine the model of EBRD, just like the second alternative, only that enrichment to the operationalization of the model will be an extra, not a reduction or simplification.

Apparently, this study has resulted in a fourth alternative. The findings have only confirmed some aspects of the proposition set; however, there are also additional points confirmed. It becomes fascinating and useful not only in enriching the urban and regional development practices about climate change mitigation but also enrich the EBRD model to be more applicable especially regarding the current issues.

\section{Findings Discussion}

Discussion in this section follows the pattern of the propositions.

\section{Are MBIs More Beneficial Than CAC?}

The stakeholders related to climate change mitigation through the LED strategy are in doubt whether MBIs could be more beneficial than CAC in the Central Java case. There are four reasons stated.

First, the implementation of the CAC has been longstanding and already entrenched for the nature of Indonesia. This reason is also admitted by an Indonesian environmental expert who works in Australia. Regarding human resources, the application of MBIs replacing the CAC will require preparation and a difficult transition. More unfortunately, even to implement the RAD-GRK that is with CAC approach, human resource is the least prepared factor in the industrial sector (Sugiri, 2015). No wonder then, among the CJPG officials responsible for the industrial development, no one is familiar with MBI approach or aware of the possibility of its application.

It is recognized by all government key persons, especially from the BLH, that the implementation of CAC indeed contains weaknesses. For example, some industries do not comply with the environmental quality standards set by the government. When these industries are monitored, they show all good aspects to be observed, such as the levels of waste/emissions are within the quality standards permitted and that all procedures of wastewater/emission treatment are done. However, when the monitoring is completed, the waste/emission management procedures are not performed correctly. Several such cases have been revealed, usually through the reports from the disadvantaged communities.

However and this is the second reason, the key persons have argued that innovation in the implementation of the CAC is always in progress and good enough to overcome the weaknesses. They do not agree if the shortcomings of the CAC could only be covered by the implementation of the MBIs. Communities, according to them, are increasingly aware of the environmental issues, supported by the environmental education and advocacy movement. So, they view that this kind of development can overcome the weaknesses. Also, a national program called the Program for Pollution Control, Evaluation and Rating (PROPER), a program to encourage performance improvement of industrial companies to be more environmentally friendly, is also deemed proven in raising awareness of the industry itself to comply with environmental standards.

The third reason is that findings from the interviews also highlight the shortcomings of the MBI application in Indonesia, namely the problem of tax non-compliance companies. It is because MBIs are highly dependent on the mechanism of taxation or other market mechanisms administered by the taxation institution. The problem of tax non-compliant companies is usually related to corruption in the form of 'collusion' in the tax reduction or tax relief and it has long been rampant in Indonesia. What have been revealed to the surface and followed up with the legal process like the case of Gayus Tambunan are believed to be only a small fraction of what happened. With that kind of corruption vulnerability, a new responsibility for the taxation system like the application of MBIs could attract new corruption.

In addition, by applying for the tradeable emission permit, for example, what if the estimate of the number of permits to be purchased by an industry is not accurate? What if it turns out later that the amount of GHG emissions released by an industry exceeds the number of licenses it has bought? Who will control and force the industry to meet its obligation? Is this not a similar weakness to the one that exists in the implementation of CAC?

The critical questions and statements from the informants, including the expert from Australia, have led to the fourth reason, which is a reformulation of taxation system concerning the MBIs is almost impossible. It will require not only increase in the capacity of human resources but also fundamental overhaul of the system. It is very difficult to realize with such taxation implementation that is still prone to corruption. More unfortunate is, no taxation officials in Semarang have agreed to be interviewed for this study. So, the prospect of taxation reformulation, which is one of the requirements for the application of MBIs, is not good shortly.

Thus, although supported by empirical evidence in developed countries and some developing countries (see e.g., Blackman and Harrington, 1999; Cotton and DeMello, 2014; Halter, 1991; Hanley et al., 2006; Oates, 1994; Suk et al., 2014; Tietenberg, 1994), particularly South Korea, that the application of MBIs can be better than the $\mathrm{CAC}$ in overcoming the problem of pollution in general 
and GHG emissions in particular, it will encounter many obstacles in Central Java and Indonesia in general. Improvement of the CAC application, therefore, would be much better than the application of MBIs replacing the $\mathrm{CAC}$, at least for the short- and medium-term.

\section{Should CAC Be Complemented with MBIs?}

The second proposition that the implementation of the CAC should be complemented by and integrated with MBI approach turned out to be confirmed regarding the principle, but not in terms of its shape, namely the tradeable emission permit. This confirmation is revealed from the interviews with sources from the BLH and manufacturing industries with high-performance in the environmentally friendly criteria.

PT Phapros for example, which follows the PROPER program since 2011 and now ranks Green (very good compliance), has been doing its improvements associated with pollution continuously. The company is gradually doing the replacement of chemicals used in the production process, either directly or indirectly, from the ingredients emitting high GHGs to those with lower GHG emissions. For example, in complying with the ban on the use of Henlon, the company has replaced Henlon with carbon monoxide that is lower in GHG emissions. For the cooling system, Freon, the refrigerant, has also been replaced with Hydrocarbons.

Additionally, fuel consumption savings are always sought by, inter alia, changing the old large-capacity generators, whose efficiency level is just $60 \%$, with new ones. As a result, the fuel consumption per litre per KWh has become more efficient so that the GHG emissions can be reduced. Additionally, energy-saving lamps have been used for lighting while for the boiler machines replacement of diesel with liquid natural gas, which is lower in GHG emissions, is in progress.

Overall, the company has managed to reduce its GHG emissions by $15 \%$ in the seven-year period, since 2008. In the future, for the $2015-2020$ period, the targeted reduction is $20 \%$.

It is interesting that all funding, including investments needed to reduce pollution and GHG emissions, is fully covered by the company. When inquired as to whether all these costs commensurate with the benefits, or there has been a decrease in the company's profit margin, quite surprising that the company's profits have even increased along with the increased ranking of the company in the PROPER program.

PROPER is a national program of the Ministry of Environment since 1995, which of course is always improving. The program assesses the environmental performance ratings of companies with high pollution and GHG emissions. There are five ranks with symbols of colors ranging from Black for companies causing environmental damage, Red for those having not been environmentally friendly yet (non-compliance), Blue for industries that already meet the minimum requirements of environmentally friendly (compliance), Green for very good performance with extra initiatives not commanded by the rules and Gold for the best or outstanding performance (Fig. 4 and 5). The rating of each company is then announced to the general public through press conferences, printed media and other communication media, including the internet. It can be said that this program is a means of education and advocacy for the environmentally conscious living for the manufacturing industries.

Two sides could explain why the financial increase due to the efforts to reduce GHG emissions can generate profit increase as well. The first is, the production becomes more efficient and effective after using materials and tools that are more environmentally friendly. Then, the profit margin would likely be higher. The second is from the consumer side, although this is just an estimate because there is no such research yet in Indonesia, namely increasing consumer awareness for the use of 'green' industrial products. It is because the environmentally conscious advocacy movement has been increasingly widespread.

One important note related to the MBIs is that companies bear the full costs to reduce GHG emissions and improve environmentally-friendly performance. In addition, companies conduct Corporate Social Responsibility (CSR) to finance environmental improvement activities such as reforestation and the development of domestic waste bank in Pringapus District, Semarang Regency.

All this shows that though not through the mechanism of taxation or tradeable permit, polluters pay principle is applied although it may not be optimal. It is because a company that has reached the Blue rank is considered compliance, so to improve the rank to Green or even Gold is just voluntary. Similarly, the reduction of the GHG emissions, according to the key person from the BLH is still voluntary. That is why, companies considered successful in reducing GHGs are those already ranked Green or Gold when starting the initiative, like PT Phapros and PT So Good.

However, the prospect of improving the CAC accommodating the market-based principle is pretty good. Nationally, this has been proven by encouraging the development of the PROPER program in raising the level of compliance with the environmental regulatory from below $30 \%$ in 1995 to around $70 \%$ in 2011 (Afsah et al., 2013). Meanwhile, in Central Java Province, its prospect in mitigating climate change seems to be able to serve as an example. It is because with the commence of RAD-GRK 2020 implementation, the target to reduce GHG emissions for the industrial sector has been defined, so the PROPER program seems to need enrichment by associating it with the LED strategy. 

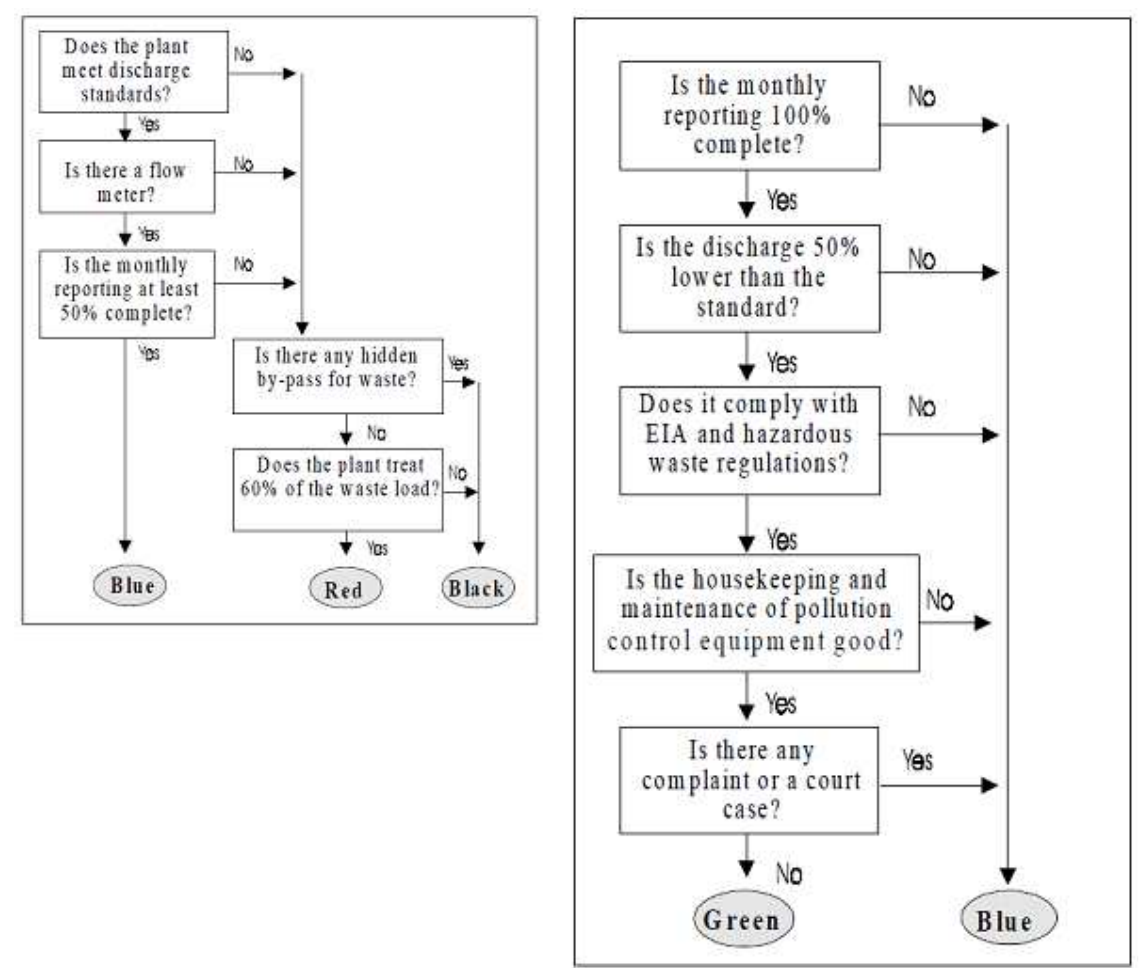

Fig. 4. The Criteria of Black, Red, Blue and Green Labels in PROPER (Afsah and Vincent 1997: 8)

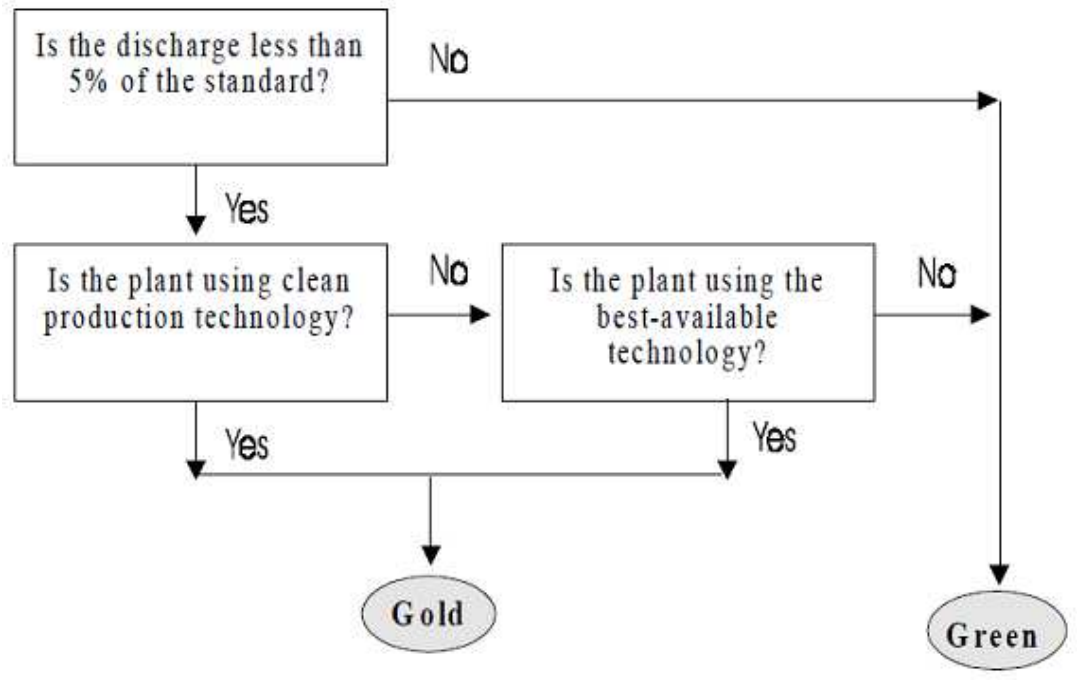

Fig. 5. Criteria Comparison of Green and Gold Labels in PROPER (Afsah and Vincent 1997: 8)

\section{Possibility of Tax Reformulation to Apply MBIs}

The taxation system should be reformulated to apply MBIs. Unfortunately, as mentioned earlier, no key persons from the taxation office in Central Java were willing to be interviewed. Thus, the discussion in this section is merely based on indirect resource persons, i.e., from the BLH, the Disperindag, the industries and the Australian expert.
Theoretically, the system of tradeable emission permits is appropriate to be applied in the early stage of integrating MBI into CAC. It is also not too difficult to reformulate the tax system so that tradeable emission permits can run. There are four important things to be considered. The first concerns the cooperation of the Ministry of Environment, Ministry of Industry and the Ministry of Finance at the national level, which is followed up with the cooperation of BLH, 
Disperindag and Taxation Office at the provincial level. It is possible considering the three authorities have often collaborated in various aspects.

Second, the environmental losses due to the negative externalities of industrial activity, in this case, related to GHG emissions, must be recognized and measured by the BLH in collaboration with the Disperindag at the provincial level. It will be the basis for setting up the price of each unit of emission permit. In this case, the challenge is big enough, especially when considering that Indonesia is not accustomed to this. What has long been practiced is to set standards of environmental and effluent quality, which according to the expert from Australia is based on the assimilative capacity of the environment. In fact, it is almost impossible for Indonesia that still needs high economic growth to stop the industrial production at the level of pollution or emission that does not exceed the assimilative capacity of the environment.

Although the CAC approach in Indonesia, supported by the PROPER program, has been complimented internationally, it must be remembered that there are still many industries having Black and Red ranks. That is to say, the environmental cost caused by these industries is to be borne by the society. According to the BLH informant, indeed there have been complaints from some people and led to legal provisions in court, but cases like this are only a few. Unfortunately, many environmental losses are not handled properly because the polluters pay principle cannot be fully implemented through the CAC.

The third one is the pricing of emission permits, which are paid by the industry through the tax mechanism. If both of the above have been established, usually through an agreement between the government and the industry, then this third one is not difficult to realize. However, it needs a reformulation of the tax system that will also involve the capacity buildings of the human resource of taxation, something that is certainly not simple.

The fourth is the institutional aspect in the implementation, especially whether it is necessary to form a special implementing agency. Then if so, whether the institution should be under the Ministry of Environment as the coordinator or another ministry is also an issue.

Considering the above four aspects, the informants have argued that the prospect of the tax reformulation is not good for short- and medium-term. It is not because of their pessimistic outlook, but because they perceive that the existing conditions make it not possible yet. Nevertheless, all informants agreed that the principles that uphold fairness, justice and equity like the principles of polluters pay and internalizing the externality should be accommodated in the implementation of the CAC.

\section{Limitations}

This study has several limitations. The first is the limited funding, which can also be found in many other studies with funding from Indonesian universities. This kind of limitation has made the researchers not able to make trips more distant than Semarang-Surakarta metropolitan areas. The second limitation is about time. It was a six-month research project. With such short period of study, the researchers could not make a proper approach and were not able to reserve more time for making appointments with and interviewing, the informants. That is why, some initially targeted key informants were failed to be interviewed, such as officials from the taxation office and key persons from the Semarang Power Plant, Batik Semar and Indofood manufacturing industries.

In addition to and related with, the time limitation, the change or the unavailability of some key informants has also limited this research. Some key persons who were initially appointed to be interviewed were later changed and this has consumed time. It was unfortunate that no key persons from the taxation office were willing to be interviewed.

Finally, although those limitations were anticipated well in advance, as they were clearly stated in the research proposal, no technical solution was ever thought by the researchers. Nevertheless, this study can be considered a necessary preliminary or pilot project.

\section{Conclusion}

To facilitate a better LED in the industrial sector of Central Java, the Provincial Government cannot apply MBIs in their original forms as in the theory. However, market-based principles in accordance with the equitybased development model should be integrated into the CAC application. They, among others, are the principle of internalizing the externality and the polluters pay principle. Existing programs, such as the PROPER, must be refined conceptually and enforced more broadly to accommodate those principles better.

One way is to link the achievement of PROPER with the development mechanisms. It has been attempted in the lending or credit system in certain banks. Industrial companies with Green or Gold rank, for example, will be facilitated by obtaining a loan from the banks easier than those ranked Blue or below. It is a good thing to be expanded, for example with PROPER mechanism linking to the procurement of goods and services. For the first phase, this could be applied for the procurement in the governmental institutions, for example by requiring bidders to be rated a minimum of Blue, or the better PROPER rank will get higher grades.

Furthermore, integrating the market-based principles into the implementation of CAC without going through the tax mechanism can be done by developing the 
concept of PROPER. One of them, for example, is by requiring a company wanting to improve the ranking from Black or Red to Blue or better to conduct a study measuring the environmental costs of the externalities of the company, including those of the GHGs, when it was still rated Black or Red and in its current situation. The study should involve adequate expertise, so it should collaborate with research institutes or universities credible in environmental sciences and sustainable development.

Studies of the environmental costs of the negative externalities can be considered very significant for such integration for mid-term and long-term future. It is possible that this integration would be a unique model of Indonesia that will be appreciated and emulated by the international community later.

So, this research can also be seen as a starting point for further related studies.

\section{Acknowledgement}

The authors would like to express much gratitude to The Faculty of Engineering of Diponegoro University for the encouragement through the fund granted for this research in 2015. Many thanks also to Ms. Ananda Kustanti Putri, who has assisted this research, especially in preparing and transcribing the interviews.

\section{Author's Contributions}

Both authors have worked as partners in this research; however, the topic idea was originated from the first author. The manuscript has been developed from the research report and mostly done by the first author.

\section{Ethics}

This manuscript is original and contains unpublished material. The corresponding author confirms that the second author has read and approved the manuscript and no ethical issues involved.

\section{References}

Afsah, S., A. Blackman, J.H. Garcia and T. Sterner, 2013. Environmental Regulation and Public Disclosure: The Case of PROPER in Indonesia. 1st Edn., Routledge, New York, ISBN-10: 1135127085, pp: 152.

Afsah, S. and J.R. Vincent, 1997. Putting pressure on polluters: Indonesia's PROPER program. Asia Environmental Economics Policy Seminar, March, Harvard Institute for International Development.

Blackman, A. and W. Harrington, 1999. The use of economic incentives in developing countries: Lessons from international experience with industrial air pollution. Discussion Paper, 99-39, Resources for the Future.
Buchner, B., M. Catenacci and A. Sgobbi, 2007. Governance and environmental policy integration in Europe: What can we learn from the EU emission trading scheme? FEEM Working Paper No. 54.

Buchori, I. and A. Sugiri, 2016. An empirical examination of sustainable metropolitan development in Semarang City, Indonesia. Australian Planner. DOI: 10.1080/07293682.2016.1151905

Buchori, I., A. Sugiri, S.P. Hadi, D. Wadley and Y. Liu. 2015. Developing a Geographic Information System-Based Assessment Model for Sustainable Metropolitan Development: The Case of the Semarang Metropolitan Region, Indonesia. American Journal of Environmental Sciences, 11 (2): 62-75. DOI: 10.3844/ajessp.2015.62.75

Cotton, D. and L. DeMello, 2014. Econometric analysis of Australian emissions markets and electricity prices. Energy Policy, 74: 475-485. DOI: 10.1016/j.enpol.2014.07.024

Creswell, J.W., 2009. Research Design: Qualitative, Quantitative and Mixed Methods Approaches. 1st Edn., Sage Publications, Thousand Oaks, ISBN-10: 1412965578, pp: 260.

Daly, H.E., 1991. Steady-State Economics. 1st Edn., Island Press, Washington, ISBN-10: 1597268720, pp: 318.

Doran, K. and A. Ginnochio, 2008. United States climate policy: Using market-based strategies to achieve greenhouse gas emission reductions. Environ. Energy Law Policy J., 3: 31-84.

Erickson, P., M. Lazarus and R. Spalding-Fecher, 2014. Net climate change mitigation of the clean development Mechanism. Energy Policy, 72: 14654. DOI: 10.1016/j.enpol.2014.04.038

Grineski, S.E., T.W. Collins, P. Ford, R. Fitzgerald and R. Aldouri et al., 2012. Climate change and environmental injustice in a bi-national context. Applied Geography, 33: 25-35. DOI: 10.1016/j.apgeog.2011.05.013

Halter, F., 1991. Toward More Effective Environmental Regulation in Developing Countries. In: Environmental Management in Developing Countries, Erocal, D. (Ed.), OECD, Paris, ISBN-13: 9789264035034, pp: 223-254.

Hanley, N., J.F. Shogren and B. White, 2006. Environmental Economics in Theory and Practice. 2nd Edn., Palgrave Macmillan, London, ISBN-13: 9780333971376, pp: 480.

Ituarte-Lima, C., C.L. McDermott and M. Mulyani, 2014. Assessing equity in national legal frameworks for REDD+: The case of Indonesia. Environ. Sci. Policy, 44: 291-300. DOI: 10.1016/j.envsci.2014.04.003

Jupesta, J., 2010. Energy, climate change and economic development: Indonesia case. USAEE-IAEE Working Paper No. 10-048. 
Kozlowski, J., 1993. UET Method: A Planning Tool for Sustainable Development. In: Towards Planning for Sustainable Development: A Guide for the Ultimate Environmental Threshold (UET) Method, Kozlowski, J. and G. Hill (Eds.), Avebury, Aldershot, ISBN-13:978-1856284677, pp: 16-32.

Liu, X., R. Yamamoto and S. Suk, 2014. A survey of company's awareness and approval of market-based instruments for energy saving in Japan. J. Cleaner Product., 78: 35-47.

DOI: $10.1016 /$ j.jclepro.2014.05.005

McDermott, M., S. Mahanty and K. Schreckenberg, 2013. Examining equity: A multidimensional framework for assessing equity in payments for ecosystem services. Environ. Sci. Policy, 33: 416-27. DOI: $10.1016 /$ j.envsci.2012.10.006

Munro, D.A., 1995. Sustainability: Rhetoric or Reality? In: A Sustainable World: Defining and Measuring Sustainable Development, Trzyna, T.C. (Ed.), International Center for the Environment and Public Policy (ICEP) for IUCN, Sacramento, ISBN-13: 978-1880028025, pp: 27-35.

Mitchell, B., 1979. Geography and Resource Analysis. 1st Edn., Longman, London, ISBN-13: 978-0582487321, pp: 399.

Oates, W.E., 1994. Environment and Taxation: The Case of the United States. In: Environment and Taxation: The Cases of the Netherlands, Sweden and the United States, OECD (Ed.), OECD, Paris, ISBN-13: 9264140611 , pp: 103-143.

O'Connor, D., 1994. Managing the Environment with Rapid Industrialisation: Lessons from the East Asian Experience. 1st Edn., OECD, Paris, ISBN-10: 9264141812, pp: 218.

Patil, R.P. and T.M. Deepa, 2007. Climate change: The challenges for public health preparedness and response-an Indian case study. Ind. J. Occupat. Environ. Med., 11: 113-115.

DOI: $10.4103 / 0019-5278.38460$
Pearce, D.W. and R.K. Turner, 1990. Economics of Natural Resources and the Environment. 1st Edn., Harvester Wheatsheaf, New York, ISBN: 0-7450-0202-1, pp: 392.

Sugiri, A., 2015. Preparedness in implementing action plan for reducing GHGs: The case of central Java. Am. J. Environ. Sci., 11: 13-27. DOI: 10.3844/ajessp.2015.13.27

Sugiri, A., 2009. Redressing Equity Issues in Natural Resource-Rich Regions: A Theoretical Framework for Sustaining Development in East Kalimantan, Indonesia. In: Environmental Ethics: Sustainability and Education, Weber, E. (Ed.), Inter-Disciplinary Press, Oxford, ISBN-13: $9781904710745, \mathrm{pp}: 107-135$.

Sugiri, A., I. Buchori and S. Soetomo, 2011. Sustainable metropolitan development: Towards an operational model for semarang metropolitan region. Int. J. Environ., Culture Economic Soc. Sustainability, 7: 301-23.

Sugiri, A. and N. Nuraini, 2013. Towards equity-based regional development: Addressing spatial inequality in the Blitar region. Int. J. Civic, Political Community Stud., 10: 91-109.

Suk, S., X. Liu, S. Lee, S. Go and K. Sudo, 2014. Affordability of energy cost increases for Korean companies due to market-based climate policies: A survey study by sector. J. Cleaner Product., 67: 208219. DOI: 10.1016/j.jclepro.2013.12.053

Tietenberg, T., 1994. Market-Based Mechanisms for Controlling Pollution: Lessons from the U.S. In: Economic Policies for Sustainable Development, Sterner, T. (Ed.), Kluwer Academic Publisher, Dordrecht, ISBN-13: 9789401043588, pp: 20-45.

WCED, 1987. Our Common Future. 1st Edn., Oxford University Press, Oxford, ISBN-13: 978-0192820808, pp: 400.

Yin, R.K., 2009. Case Study Research: Design and Methods. 4th Edn., Sage Publication, Thousand Oaks, ISBN-13: 978-1412960991, pp: 240. 